\title{
Decision-making in crisis resolution and home treatment teams: The AWARE framework
}

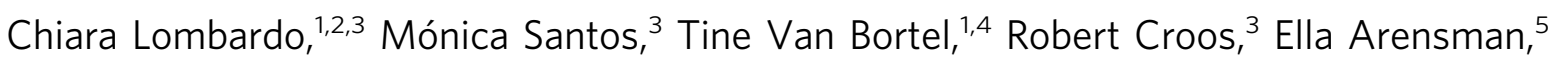 \\ Manaan Kar Ray ${ }^{3,6,7}$ (D)
}

BJPsych Bulletin (2019) 43, 61-66, doi:10.1192/bjb.2018.94

\author{
Institute for Health and Human \\ Development, University of East London, \\ UK; ${ }^{2}$ Research and Development, \\ Mental Health Foundation, UK; ${ }^{3}$ Adult \\ Mental Health Services, Cambridgeshire \\ and Peterborough NHS Foundation \\ Trust, UK; ${ }^{4}$ Cambridge Institute of Public \\ Health, University of Cambridge, UK; \\ 5 School of Public Health, National \\ Suicide Research Foundation, University \\ College Cork, National University of \\ Ireland, Ireland; ${ }^{6}$ Addictions and Mental \\ Health Services, Princess Alexandra \\ Hospital, Metro South, Australia; \\ ${ }^{7}$ Southside Clinical Unit, Princess \\ Alexandra Hospital, University of \\ Queensland, Australia \\ Correspondence to Dr Manaan Kar Ray \\ (manaan.karray@health.qld.gov.au) \\ First received 7 Mar 2018, final revision \\ 19 Oct 2018, accepted 19 Oct 2018 \\ (C) The Authors 2018. This is an Open \\ Access article, distributed under the \\ terms of the Creative Commons \\ Attribution-NonCommercial- \\ NoDerivatives licence (http:// \\ creativecommons.org/licenses/by-nc- \\ nd/4.0/), which permits non- \\ commercial re-use, distribution, and \\ reproduction in any medium, provided \\ the original work is unaltered and is \\ properly cited. The written permission of \\ Cambridge University Press must be \\ obtained for commercial re-use or in \\ order to create a derivative work.
}

Aims and method The aim of the study is to improve patient safety by identifying factors influencing gatekeeping decisions by crisis resolution and home treatment teams. A theoretical sampling method was used to recruit clinicians. Semi-structured interviews to elicit various aspects of clinical decision-making were carried out. The transcripts were thematically analysed using a grounded theory approach.

Results Patient needs (safety and treatment) was the primary driver behind decisions. The research also revealed that information gathered was processed using heuristics. We identified five key themes (anxiety, weighting, agenda, resource and experience), which were constructed into an acronym 'AWARE'.

Clinical implications AWARE provides a framework to make explicit drivers for decision-making that are often implicit. Incorporating these drivers into reflective practice will help staff be more mindful of undue influences and result in improved clinical decisions.

\section{Declaration of interest None.}

Keywords Clinical decision-making; crisis resolution and home treatment teams; clinical assessment.
Crisis resolution and home treatment teams (CRHTTs) are the interface between acute and community mental health services. Focused on patients' recovery and empowerment, they are an alternative to hospital admission, providing treatment in a less restrictive environment. They are the gatekeepers for in-patient admissions and enable early discharge, reducing hospital bed use. ${ }^{1,2}$ Patients experiencing mental health crisis are assessed by CRHTT practitioners. Outcomes may include home treatment, admission to hospital, back to referrer in secondary or primary care or signposting to other appropriate services. ${ }^{3,4}$

Now an integral part of mental health services in the UK, ${ }^{5}$ they were introduced in $1999^{2}$ through the National Service Framework for mental health in England. Similar teams have been implemented in other European countries. ${ }^{6}$ Research has primarily focused on their value as admission prevention service. Some, ${ }^{7-9}$ but not all, ${ }^{10}$ studies indicate reduction in bed use. National guidance ${ }^{\mathrm{ll}}$ on acute service provision recommends CRHTTs. A systematic review of 69 studies ${ }^{12}$ identified elements influencing CRHTT service quality through models of care and implementation guidelines. Hunt et $a l^{13}$ has noted that suicide rates in crisis teams are higher than in in-patient settings. CRHTT decisions are at a critical juncture in the care pathway and have a major impact on patient outcomes, but research is scarce and needs development.

Clinical decision-making is a contextual, continuous, evolving process, where data is gathered, interpreted and evaluated to select evidence-based actions. ${ }^{14}$ Understanding the rationale behind CRHTT assessment outcomes, such as whether to admit a patient, is pivotal to improving patient safety. We conducted a qualitative study with the aim of identifying intuitive 
factors influencing clinical decision-making following CRHTT assessments, as a service improvement project.

\section{Method}

\section{Setting and participants}

A theoretical sampling method was used to identify qualified multidisciplinary team members in a CRHTT of working-age adults in East Anglia. Eighteen interviews were carried out across 12 multidisciplinary team staff (10 nurses, 2 social workers; post-qualification experience: $10-25$ years; 6 men, 6 women), who were primary assessors. Six participants were interviewed once and six participants were interviewed twice.

Psychiatrist were not included as their involvement in clinical decision-making in the initial assessment was not routine in this team. Participants volunteered after being informed of project objectives and procedures and provided verbal informed consent. It was only after the conclusion of the clinical interaction that assessors participated in the study, thus there was no direct or indirect influence on patient care. As part of the consent process, interviewees were given specific instructions not to use any patient-identifiable information. This was in keeping with the organisation's confidentiality policy.

Ethical approval was not deemed necessary and the study was registered within the trust as a service improvement project.

\section{Interviews}

Semi-structured, face-to-face interviews (supplementary interview schedule available at https://doi.org/10.1192/bjb. 2018.94) with open-ended questions to elicit various aspects of clinical decision-making were carried out separately by two psychiatrists working in the CRHTT (M.S. and R.C.). Participants were asked to discuss an assessment from the past $24 \mathrm{~h}$. The interview schedule provided general structure but the discussion was fluid based on the responses, which were probed to gain a deeper understanding of the themes and theories being generated. Each interview lasted about 1 hour. Interviews were audio-typed, transcribed and conducted until saturation of themes was reached.

\section{Data analysis}

A grounded theory approach was taken. ${ }^{15,16}$ Data was thematically analysed by the researchers (M.S. and R.C.) working independently, following recommendations by Ritchie et al. $^{17}$ Initial transcripts were coded manually to support development of a coding framework that was subsequently refined by additional interviews. Codes included purely descriptive ones arising directly from the transcript and more interpretive codes. Then, to ensure trustworthiness of the data, the authors met and agreed themes. Any differences in interpretation of statements was resolved by discussion with the wider research team until consensus was reached. The coded data was synthesised into the final framework. Further confirmation of themes took place through team discussion, with themes validated by an independent researcher (C.L.) and the principal investigator (M.K.R.).

\section{Results}

Of the 18 assessments, low mood and suicidality appeared to be the primary cause of referral to CHRTT. Information gathered relating to symptom severity and risk appeared to be the primary basis for decision-making. Information from the referrer was supplemented by electronic patient records or past knowledge about known patients. The principal source was the face-to-face assessment with the person and their carer/s. Patient need (actual or perceived) appeared to be the primary driver behind decisions. This was evidenced in statements such as: 'For her own safety, she was unpredictable, it would have been difficult to manage that in the community at that time...Admission was the right decision' (01). (For all quotations, the numeral refers to the interview serial number.)

However, interviews revealed that the extensive information gathered was not processed in a uniform manner, but often by heuristics (common sense, rule of thumb, stereotyping, educated guess, intuitive judgement). These were noted to be part of the decision-making toolbox for all practitioners and were related to more than just patient presentation (symptoms, risk, aetiology). Below, we describe the most commonly expressed heuristic themes that influenced decision-making (Table 1).

\section{Anxiety}

Interviews clearly showed the dual role of practitioners. First, to assess and plan the next steps, and second, to diffuse anxiety relating to the crisis under assessment. For

\begin{tabular}{|c|c|}
\hline Theme & Subtheme \\
\hline \multirow{4}{*}{$\begin{array}{l}\text { Anxiety (generated/ } \\
\text { diffused in) }\end{array}$} & Patient \\
\hline & Friends/family/carer \\
\hline & Referrer \\
\hline & Triaging/assessing practitioner \\
\hline \multirow[t]{3}{*}{$\begin{array}{l}\text { Weighting (of } \\
\text { symptoms elicited) }\end{array}$} & $\begin{array}{l}\text { Diagnosis (comorbidity - personality } \\
\text { disorder/alcohol or substance misuse) }\end{array}$ \\
\hline & $\begin{array}{l}\text { Course of illness (acute/chronic/acute on } \\
\text { chronic) }\end{array}$ \\
\hline & $\begin{array}{l}\text { Factors considered outside core remit } \\
\text { (relationship/finances/accommodation/ } \\
\text { employment/family - carer availability) }\end{array}$ \\
\hline \multirow[t]{5}{*}{ Agenda (elicited in) } & Referrer \\
\hline & Patient \\
\hline & Family \\
\hline & Practitioner \\
\hline & Team \\
\hline \multirow{2}{*}{$\begin{array}{l}\text { Resources (identified } \\
\text { or not) }\end{array}$} & Beds \\
\hline & Home treatment capacity \\
\hline \multirow[t]{3}{*}{ Experience (of) } & $\underline{\text { Same patient }}$ \\
\hline & $\begin{array}{l}\text { Other patients from same diagnostic } \\
\text { group }\end{array}$ \\
\hline & $\begin{array}{l}\text { Other patients from different diagnostic } \\
\text { group }\end{array}$ \\
\hline
\end{tabular}


the patient and family the anxiety settled when they felt that they got the right support, the referrer felt less anxious knowing someone else was dealing with the crisis and the assessor's anxieties settled if they felt they had brought matters to a safe conclusion either through capturing hope or blanket safety reassurances. In the case of a young, agitated suicidal male with limited protective factors who was referred back to locality team, the practitioner stated, Well it was straightforward, he was able to engage in it (the assessment) despite the difficulties with his anxiety' (03). The patient's willingness to engage was indicative of a safe conclusion. It diffused everyone's anxiety and trumped symptoms of agitated depression and the rationale for the decision not to provide additional support. A similar presentation with an ambiguous commitment resulted in higher anxiety all around, bringing forward the diametrically opposite decision to admit: '... There was obviously some urgency to it (admit). He had strong thoughts of taking an overdose the previous day....and his wife had to take time off work because she was concerned about his help-seeking' (15).

Practitioners were consciously eliciting predisposing, precipitating and perpetuating factors as part of exploring risk (increases anxiety), as well as protective factors and the potential willingness to safety plan (decreases anxiety). It was noted that in patients with similar presentations and risk profiles. there could be diametrically opposite clinical decisions. For risk-averse decisions, the focus was on anxiety increasing perpetuating factors. In contrast, anxiety decreasing protective factors were emphasised by the assessor. where they had taken positive risks: '. ..He was staying with his parents, they were quite supportive, ... housing was a big concern.... but he's got a good job, and his employer had been really supportive. He also identified his daughter and his father as protective factors' (14).

\section{Weighting}

In the decision-making process, weighting of symptoms and risk was influenced by pre-existing diagnosis (personality disorder/substance misuse), course of illness (acute, acute on chronic, chronic) and presence or absence of social factors that were considered to be outside the core remit of CRHTT work. For example, in a suicidal patient who was not taken on, the practitioner stated: 'Not much had changed. He had previously been referred to the [...] service and the $[. .$.$] service...he'd already been signposted, nothing$ had changed' (12).

Patients with alcohol and/or substance misuse fell into a similar bracket, with the understanding that these issues needed to be addressed first by other agencies: 'He's a heavy cannabis user, which he uses to self-medicate with his anger difficulties. We gave him advice on alcohol making him impulsive, what else can we do' (02). Nevertheless, substance misuse issues were consistently assessed for, and when identified, appropriate onward referral/signposting took place. In the presence of clear-cut major psychiatric illness, comorbid substance misuse was taken very seriously as it is a factor that significantly contributed to increased risks: '...She has been abstinent for [...] years now but with all the stress going on in the family she had turned to drink, it's only when she drinks she takes an overdose. It makes her feel lower and more impulsive, we had to do something to break the spiral' (05).

The course of the illness also strongly influenced the outcome. Generally, an acute presentation appeared to trump an acute on chronic presentation, which was higher on the pecking order to a chronic deterioration irrespective of the presentation and risk being quite similar; the expectation in the latter being that more should be done by the referrer.

Acute: '...She was presenting as quite labile... was quite unsettled, agitated, disinhibited...we have to do something' (01).

Acute on chronic: '. . .She's got chronic thoughts of ending her life by an Insulin overdose. There's a change to wanting to put herself in front of a train...previously what stopped her acting was her sons, however this had changed. The intensity had changed and a change in nature. Her protective factors have reduced' (15).

Chronic: 'I didn't think it was an appropriate referral because this was a guy who'd only been seen in an out-patient appointment with long-term ongoing problems and I felt more could have been done by the locality team, before referring' (03).

Although practitioners fully recognised the impact on risk of social factors (accommodation, finances, relationships, employment, carer/family support and availability), those presenting primarily with these issues were often not taken on for acute care interventions. In these circumstances, often the social aetiology behind the crisis was given more weighting than the risk: '...Social support impacted the decision-making...no significant friends or family. She receives no support from care services with regard to her son. . . She is single, financially lacking and on benefits, lacking social support. She has physical illnesses with a lot of symptoms...but not for us really...' (16).

\section{Agenda}

Agendas (desire to achieve a particular outcome), both stated and perceived, influenced information processing. If an agenda was picked up in a referrer/patient/carer by a practitioner, they often responded to it. This was most obvious when judgement calls were being made about the appropriateness of the referral: '...I felt that the reasons for the referral weren't really appropriate. He was someone that they'd (Locality Team) only seen twice, the reason for referral was that he was being actively suicidal. But I felt the risk was kind of raised so we'd go and see him...' (06).

Sometimes agendas were picked up in patients and carers. There was evidence to suggest that practitioners responded (taking seriously or dismissing) with their gut instinct to the agenda that they perceived: '. . . Suicidal ideation, in the context of depression...because she has a child, so I think it's always worth having a look when there's a child, I got the clear sense that she was downplaying it as she did not want social services involved, we needed to do something...' (13). Generally carer concerns particularly relating to burnout were taken quite seriously, as delivering successful home treatment is often quite difficult without their support: 'I think her husband felt that she needed to come into hospital...he was quite distressed by what she had done again. He felt it was a heavy load to carry at the moment. Too much to cope with...' (01). 


\section{Resources}

The research revealed that most practitioners were conscious about the impact of resources on decision-making. Most took the stance that they tried their level best to carry out the assessment independently of the bed state. When directly asked about bed pressures influencing decisions, most practitioners said no; however, most would be aware of it when doing the assessment. Practitioners indicated that if a patient was very unwell they would ensure that they get a bed, but it was also apparent that the threshold for admission dropped if more beds were available: 'We knew there was a bed, actually we knew there were plenty of beds on the ward, so we kind of thought, you know what this lady could just do with a break and some more assessment of her depression' (04).

There were similar findings relating to home treatment capacity, where practitioners denied the effect of resource limitation: 'It had no bearing on the decision (not to take a suicidal patient on for home treatment). What does that mean if we were short staffed we wouldn't have taken him? No it had no bearing on it whatsoever' (03). However, thresholds were noted to fluctuate in a similar fashion to beds when the home treatment team was less busy.

\section{Experience}

Past experience of unsuccessful home treatment or an admission that did not benefit the recovery journey of the patient influenced the practitioners reading of current risk. The rationale for not taking a suicidal patient on to home treatment was as '...There were no changes in his social situation from when I'd last seen him [...] years ago...if he feels that the situation is not validated then he will increase his risk behaviours... I felt that we needed to validate his level of distress over that and try and keep it compact (not get another team involved)' (17). It was also apparent that the team put a far higher premium on knowledge held within the team from previously working with a patient than what was being handed over to them in the here and now by the referrer.

\section{Discussion}

MacNeela et $a l^{18}$ concluded that nurses strive to know the patient', while having to 'work the system', with implications for patient care and decision-making quality. Interviews revealed that assessing practitioners are often put in very difficult scenarios and need to respond to multiple pressures. It would be unrealistic to expect that they will not be influenced by this. It could lead to formulation of an opinion about what a good outcome would look like early in the process. They try to remain in a rational space and make decisions based on information that they have collated. However, the pressures set up a rationalising environment in which facts get highlighted selectively to rationalise the decision that has been already formulated. This is often an unconscious process and the purpose of the study was to identify and make explicit drivers for decision-making that are often implicit and are captured in hard-to-define terms like 'gut' or 'instinct'. To help assessing staff become more mindful and stay in a rational space rather than rationalising (we see what we want to see to help us deal with our cognitive dissonance ${ }^{19}$ ), we have framed the findings from our qualitative study in an easy-to-remember acronym, AWARE (Anxiety, Weighting, Agenda, Resources, Experience).

If a practitioner is anxious about adversely affecting the balance of hope versus risk and decides not to tease out triggers extensively, this decision should be a conscious choice (rather than unconscious). One can then document the same and handover to the next person, making it clear that there is an outstanding piece of work. The assessor can then mindfully safety plan and systematically attend to warning signs ${ }^{20}$ that may rise until the next appointment. Further work relating to fluctuating risk can then be taken up when the crisis is more contained at the follow-up. Seeking blanket reassurance by asking patients 'Can you keep yourself safe?' only decreases anxiety in the practitioner and does very little to enhance safety.

Embedding reflective practice will keep clinicians mindful about these heuristics. Bhugra et $a l^{21}$ found in a qualitative study that expert psychiatrists relied upon intuitions and novices took a more analytical approach in making clinical decisions. CRHTTs are multidisciplinary in nature: front-line assessments are done by team members from different backgrounds with different levels of experience. Given the variation, decision-making standardisation becomes a key service issue. Bhugra et $a l^{21}$ found that uncontrollable factors (time pressures, cost, resources) influenced decisions. This is highly relevant as CRHTTs are often managing bed pressures. It is a highly dynamic setting, and thorough conscious deliberation on findings may not be possible. ${ }^{22}$ Hunt et $a l^{23}$ reported suicide rates of 14.6 per 10000 CRHTT episodes compared with 8.8 for in-patient episodes. The national reduction of $17 \%$ in mental health bed numbers from 2012 to $2015^{24}$ has meant that CRHTTs have an ever-increasing importance in care delivery of acutely unwell patients. Therefore the higher suicide rate in CRHTTs compared with in-patients needs urgent attention. The AWARE framework may provide the foundation for safer care as it seeks to keep assessors in a mindful and reflective space.

Hunt et $a l^{13}$ found that $49 \%$ of CRHTT patients who took their own life had adverse live events, and a further $44 \%$ were living alone. Preconceived notions about what is core CRHTT work could be taken up in case-based discussions in a supportive fashion. This could also help reframe the CRHTT gatekeeping agenda. Assessments are about admitting at the appropriate time so that the shortest in-patient stay may be followed up by prompt home treatment. It is not about keeping everyone out. Resource-led decisions ${ }^{21,25}$ are never ideal but are inevitable in the real world. Naming the decision for what it is will ensure that practitioners then consciously work toward mitigating the risk the resource-led decision has created, rather than justify (deal with cognitive dissonance ${ }^{19}$ ) their action by selectively highlighting aspects of the presentation.

Given that suicide is a rare outcome, assessors often feel that their judgement calls are safe, and so the threshold for admission/home treatment unconsciously creeps up. Reflective practice could keep staff mindful about small increments in risk-taking. Serious untoward incidents have 
a considerable detrimental impact on the confidence of practitioners to take positive risks. Threshold awareness supports safety and patients' recovery journeys in the long run, as without risk there is no recovery.

\section{Limitations}

The study findings, particularly in relation to anxiety, are limited to the CRHTT setting as crisis referrals often have an urgency and acuity that might not be present in routine assessments. As an improvement project, the findings are relevant to the service. Before generalising findings to all assessments, AWARE as a framework needs further research. It is also important to acknowledge that, for practical reasons, study participants were recruited from a single team. Although not unusual for CRHTTs, there were no front-line assessors working who had less than 10 years post-qualification experience. Research into decision-making shows that experience level has a bearing. ${ }^{21}$ Also, in most crisis services, initial assessments are carried out by nurses and social workers; however, there are teams where psychiatrists might have oversight. Inter-team variability of this nature limits the generalisability of this study. Another limitation is that interviews were carried out by CRHTT psychiatrists, introducing a potential bias in responses. This was mitigated by assuring participants that this was not an assessment of their decision-making skills and that their participation was voluntary and they could withdraw consent at any point.

Clinical decisions not only affect patient outcomes but also have significant medicolegal implications. Mulder et al point out the futility of risk categorisation and how it may confuse clinical thinking. ${ }^{26}$ This study proposes AWARE as a theoretical framework that supports safer clinical decisionmaking. To substantiate this claim, research across various contexts and different CRHTT settings is needed in which AWARE is empirically tested and refined.

In conclusion, there is a subjective element to clinical decision-making, as it involves clinical judgement and interpretation of information. However, there needs to be a balance between fact and intuition, and dissecting out intuitive processes might help eliminate certain unhelpful biases. AWARE provides a framework to make explicit some of the drivers for decision-making that are often implicit. This can be used in reflective practice groups as well as for a quick, internal crosscheck post-assessment. It may reduce bias and inter-assessor variability, improve consistency, lead to a more systematic approach and help staff be more mindful of how they could be subject to undue influences, and therefore result in improved clinical decisions and patient safety.

\section{Supplementary material}

Supplementary material is available online at https://doi.org/10.1192/bjb. 2018.94

\section{Acknowledgements}

We thank the home treatment staff who were interviewed for this study, and Mrs Mary Henniker for transcribing the interviews. We acknowledge scholarly contributions from Dr Golam Khandaker and Dr Claire Dibben.

\section{About the authors}

Chiara Lombardo, Research Fellow in Global Mental Health, Institute for Health and Human Development, University of East London Senior Research Officer, Research and Development, Mental Health Foundation and Research Associate, Adult Mental Health Services, Cambridgeshire and Peterborough NHS Foundation Trust, UK; Mónica Santos, Locum Consultant Psychiatrist, Adult Mental Health Services, Cambridgeshire and Peterborough NHS Foundation Trust, UK; Tine Van Bortel, Professor of Global Mental Health, Institute for Health and Human Development, University of East London; and Principal Investigator, Cambridge Institute of Public Health, University of Cambridge, UK; Robert Croos, Fixed Term Specialty Doctor, Adult Mental Health Services, Cambridgeshire and Peterborough NHS Foundation Trust, UK; Ella Arensman, Professor and Director of Research, School of Public Health, National Suicide Research Foundation, University College Cork, National University of Ireland, Ireland; Manaan Kar Ray, Consultant Psychiatrist, Adult Mental Health Services, Cambridgeshire and Peterborough NHS Foundation Trust, UK; Medical Director, Mental Health, Addictions and Mental Health Services, Princess Alexandra Hospital, Metro South; and Senior Lecturer, Southside Clinical Unit, Princess Alexandra Hospital, University of Queensland, Australia.

\section{References}

1 Laugharne R, Shankar R. Quality standards for community mental health teams. Psychiatr Bull 2009; 33(10), 387-89.

2 Department of Health. A National Service Framework for Mental Health Department of Health, 1999 (https://www.gov.uk/government/ uploads/system/uploads/attachment_data/file/198051/National_ Service_Framework_for_Mental_Health.pdf)

3 Lloyd-Evans B, Paterson B, Onyett S, Brown E, Istead H, Gray R, et al. National implementation of a mental health service model: a survey of Crisis Resolution Teams in England. Int J Ment Health Nurs 2017; 27: $214-26$

4 Cresswell EJ, Hodge S, Hailey E. Home Treatment Accreditation Scheme (HTAS) Standards for Home Treatment Teams (1st edn). Royal College of Psychiatrists, 2013.

5 Williamson P, Marshall L, Planning C, Manager P. A Review of Crisis Resolution Home Treatment Services In Scotland. NHS Scotland, 2011.

6 Karlsson B, Borg M, Eklund M, Kim HS. Profiles of and practices in crisis resolution and home treatment teams in Norway: a longitudinal survey study. Int J Ment Health Syst 2011; 5(1): 19.

7 Johnson S, Nolan F, Hoult J, White IR, Bebbington P, Sandor A, et al. Outcomes of crises before and after introduction of a crisis resolution team. Br J Psychiatry 2005; 187: 68-75.

8 Tyrer P, Gordon F, Nourmand S, Lawrence M, Curran C, Southgate D, et al. Controlled comparison of two crisis resolution and home treatment teams. Psychiatrist 2010; 34(2): 50-4.

9 Dibben C, Saeed H, Stagias K, Khandaker GM, Rubinsztein JS. Crisis resolution and home treatment teams for older people with mental illness. Psychiatr Bull 2008; 32(07): 268-70.

10 Jacobs R, Barrenho E. Impact of crisis resolution and home treatment teams on psychiatric admissions in England. Br J Psychiatry 2011; 199 (1): $71-6$

11 Joint Commissioning Panel for Mental Health. Guidance for Commissioners of Acute Care: Inpatient and Crisis Home Treatment. Royal College of General Practitioners and Royal College of Psychiatrists, 2013 (http:// www.jcpmh.info/wp-content/uploads/jcpmh-acutecare-guide.pdf).

12 Wheeler C, Lloyd-Evans B, Churchard A, Fitzgerald C, Fullarton K Mosse L, et al. Implementation of the Crisis Resolution Team model in adult mental health settings: a systematic review. BMC Psychiatry 2015; $15: 74$.

13 Hunt IM, Appleby L, Kapur N. Suicide under crisis resolution home treatment - a key setting for patient safety. BJPsych Bull 2016; 40(4): 172-4. 
14 Tiffen J, Corbridge S, Slimmer L. Enhancing clinical decision making: development of a contiguous definition and conceptual framework. J Prof Nurs 2014; 30: 399-405.

15 Corbin J, Strauss A. Techniques and Procedures for Developing Grounded Theory (4th edn). SAGE Publications, 2015.

16 Miles MB, Huberman AM, Saldana J. A Methods Sourcebook (3rd edn). SAGE Publications, 2014.

17 Ritchie J, Lewis J, Nicholls CMN, Ormston R. Qualitative Research Practice: A Guide for Social Science Students and Researchers (2nd edn). SAGE Publications, 2013

18 MacNeela $P$, Scott A, Treacy P, Hyde A. In the know: cognitive and social factors in mental health nursing assessment. J Clin Nurs 2010; 19(9-10): 1298-306.

19 Festinger L. Cognitive dissonance. Sci Am 1962; 207(4): 93-106.

20 Yager JL, Feinstein R. General psychiatric management for suicidal patients, with remarks on chronicity: contending with the angel of death. J Nerv Ment Dis 2017; 205(5): 419-26.

21 Bhugra D, Easter A, Mallaris Y, Gupta S. Clinical decision making in psychiatry by psychiatrists. Acta Psychiatr Scand 2011; 124(5): 403-11.
22 Bhugra D. Editorial: thinking shrinks: decision making in psychiatry. Int J Soc Psychiatry 2010; 56(5): 459-61.

23 Hunt IM, Rahman MS, While D, Windfuhr K, Shaw J, Appleby L et al. Safety in crisis resolution home treatment services in England: an investigation of suicide trends 2003-2011. Lancet Psychiatry 2014; 1(1): 135-41.

24 NHS Benchmarking Network, Inpatient and Community Mental Health Benchmarking. Vol. 36. NHS, 2016 (https://www.nhsbenchmarking. nhs.uk/projects/mental-health-inpatient-and-community-services).

25 Bickley H, Hunt IM, Windfuhr K, Shaw J, Appleby L, Kapur N. Suicide within two weeks of discharge from psychiatric in-patient care: a case control study. Psychiatr Serv 2013; 64: 653-9.

26 Mulder R, Newton-Howes G, Coid J. The futility of risk prediction in psychiatry. Br J Psychiatry 2016; 209: 271-2. 